\title{
GERÊNCIA PARTICIPATIVA: \\ UMA PROPOSTA PARA MUDANÇA DE AMBIENTE NO SERVIÇO DE ENFERMAGEM
}

Lourdes Emnia Ruviaro Novakoski *

Liliian Daisy Gonçalves Wolff **

\begin{abstract}
RESUMO - O presente estudo envolve um conjunto de reflexões sobre a cultura e sua repercussão no modelo organizacional e no estilo de gerência. Aplicando-se dois instrumentos de coleta de informações: um questionário para exame da cultura e um roteiro de entrevista, foram obtidos dados complementares quanto à situação interna e organização do Serviço de Enfermagem. Os resultados evidenciaram que a situação real é entremeada por um clima diretivo e neutro, com centralização do poder e pouca participação dos subordinados no processo decisório; enquanto que a situação desejada corresponde a um ambiente com espirito de equipe, certa flexibilidade e mobilidade e, transparência nos canais de comunicação. A partir do diagnóstico, buscou-se uma estratégia de ação que possibilitasse renovação da cultura e desenvolvimento da capacidade gerencial numa organização flexível e descentralizada.
\end{abstract}

\begin{abstract}
The present study envolves a group of reflections about the culture and its repercussions on the organizational model and on the manegement style. It has been applied two tools for information collecting. A question form to examine culture and interview follow-up. By these means, it has been obtained complementary data as to the internal situation of nursing service. The results have shown that the real situation is kneet by a neutral and direct climate, with power centralization and a little participarion in decision process as to the desireble situation related to great team habitat, a certain flexibility and mobility and transparances in comunication channel. Starting with diagnosis, the strategy of action that could renew culture has been searched and development of manegement skills in a recentralized and flexible organization as well.
\end{abstract}

\section{INTRODUÇĀO}

Cultura é um todo complexo, que envolve conhecimentos, crenças, valores, sentimentos, hábitos, necessidades, artes, leis, costumes e outras capacidades adquiridas pelo homem como integrante da sociedade. São as concepções geradoras das forças condicionantes, das quais resultam gerências e organização.

A renovação das instituições, pressupõe uma abordagem que contemple três indicadores essenciais, como:

- trabalho sobre a cultura;
- revisão do modelo organizacional; e

- reformulação do estilo gerencial.

Partindo desses pressupostos, o primeiro passo a ser dado é o diagnóstico da realidade contextual, com o objetivo de sondagem profunda da realidade.

O diagnóstico é um instrumento indispensável à gestão e ao processo. de tomada de decisão, pois é através dele que são identificados os aspectos com os quais a organização está ganhando, onde está perdendo e onde deve me-

* Enfermeiro, Economista, Mestre em Educaçảo, Docente da Universidade Federal do Paraná.

** Enfermeiro, Esp. Enf. Mǿdico-Cirúrgica e Docente da Universidade Federal do Paraná. 
lhorar. Permite uma visão global, indicando as insuficiências e permitindo prever instabilidades e avaliar desequilibrios futuros. Para compreender as organizaçōes e adminisura-las efetivamente e essencial deter-se no exame de sua cultura.

O estudo da cultura da organização, como referência estratégica para a eficácia, envolve aspectos relevantes ao passado da organização, correlacionados à situação presente e a consideração do futuro. $O$ passado, sua tradição, os hábitos e costumes, normas e procedimentos, crenças e valores e as conquistas obtidas nos processos de sobrevivência e expansão. A situação presente, o clima interno, os desafios do ambiente externo, a tecnologia de trabalho, objetivos, metas, políticas, estilo e desenvolvimento gerencial e a integração das lideranças. A consideração do futuro, com a estratégia de desenvolvimento definida.

Esses momentos se complementam e vão compondo uma cultura organizacional própria e em função desta cultura, estabelecem-se estruturas e sistemas eficazes na medida em que traduzem o espírito e os traços culturais da organização.

A cultura exerce influência marcante na conduta da organização, visto que as pessoas agem de acordo com as concepções e percepçōes que têm da realidade. AQUINO' alerta que, se a cultura não for sadia a alternativa é tentar mudá-la, inoculando valores correspondentes aos objetivos que se pretende alcançar mediante estratégias de comunicação que envolvam toda a organização.

\section{METODOLOGIA UTILIZADA PARA O DIAGNÓSTICO DA CULTURA DO SERVIÇO DE ENFERMAGEM}

Para o exame da ctultura da organização foram questionados 21 (vinte e um) enfermeiros mediante a aplicação de um questionário composto de dez questões, focalizando os seguintes aspectos: obtenção dos resultados pela empresa; lucros e despesas da organização; produtividade do pessoal; planejamento; controle; coordenação; avaliação e crítica; comunicação; tratamento e solução de conflitos; e por último, criatividade. (ANEXO 1).

Esse instrumento possibilitou detectar a cultura organizacional, revelando o ambiente e estilos gerenciais da empresa, bem como o grau de mobilidade e flexibilidade.

Os participantes do estudo, ao examinarem $o$ instrumento, deveriam emitir duas respostas: uma, correspondendo à situação real e outra, à situação dese jável.
Para a realização deste estudo, dedidiu-se examinar a cultura organizacional de um hospital de ensino, sob a ótica dos enfermeiros-chefes de unidades ambulatoriais e de internação, uma vez que a imagem projetada por esses respondentes reproduz, em parte, fatores vivenciados e introjetados pelos demais elementos da equipe de enfermagem.

Visando ao Diagnóstico situacional do campo da pesquisa, complementar às informações obtidas através do instrumento do exame da cultura, realizou-se uma entrevista com os 21 (vinte e um) participantes do estudo.

Para isso utilizou-se um Roteiro de Entrevista, composto de 18 (dezoito) itens, focalizando aspectos relacionados ao cargo ocupado, organização do serviço, plane jamento, tomada de decisão, supervisão, comunicação, controle e desenvolvimento de recursos humanos (ANEXO 2).

Convém salientar que outros dados relevantes para o estudo foram obtidos na entrevista, mesmo não tendo sido contemplados no roteiro, por manifestação espontânea dos entrevistados.

\section{APRESENTAÇĀO DOS RESULTADOS}

Nesta etapa do trabalho, optou-se em apresentar os resultados diagnósticos separadamente, embora complementares, com o objetivo de caracterizar pontos importantes relaconados à cultura e outras percepções dos respondentes.

\subsection{Diagnóstico da Cultura: Situaçāo real}

Os dados obtidos revelam os seguintes ambientes organizacionais: diretivo e neutro.

O ambiente diretivo caracteriza-se por haver pouca participação dos subordinados com centralização do poder e da tomada de decisão nos níveis superiores da empresa. Os subordinados apenas cumprem as ordens recebidas, sem exercer criatividade ou inovaçăo. Quanto mais baixa a posição nos diversos niveis hierárquicos, maior o grau de insatisfação e descontentamento.

O gráfico 1, possibilita uma visualizaçảo da configuração do ambiente cultural encontrado.

$O$ ambiente neutro caracteriza-se pelo distanciamento entre a alta direção e os demais componentes da pirâmide organizacional. A política e a filosofia da organização; bem como as funções dos diversos serviços não são claramente definidos e nem conhecidos pelos subordinados. Existe tratamento diferenciado aos diversos serviços, dando prioridade aos altamente especializados em detrimento dos serviços ope- 
racionais, cuja tecnologia e natureza do trabalho são simples e rotineiras.

Apesar deste ambiente, surgem tentativas isoladas, mas pouco produtivas, em levar o seu trabalho adiante.

Gráfico 1 - Configuração do Ambiente Real
O moral do pessoal é geralmente baixo, sendo necessário, para que a instituição sobreviva, pessoas responsáveis e identificadas com a mesma.

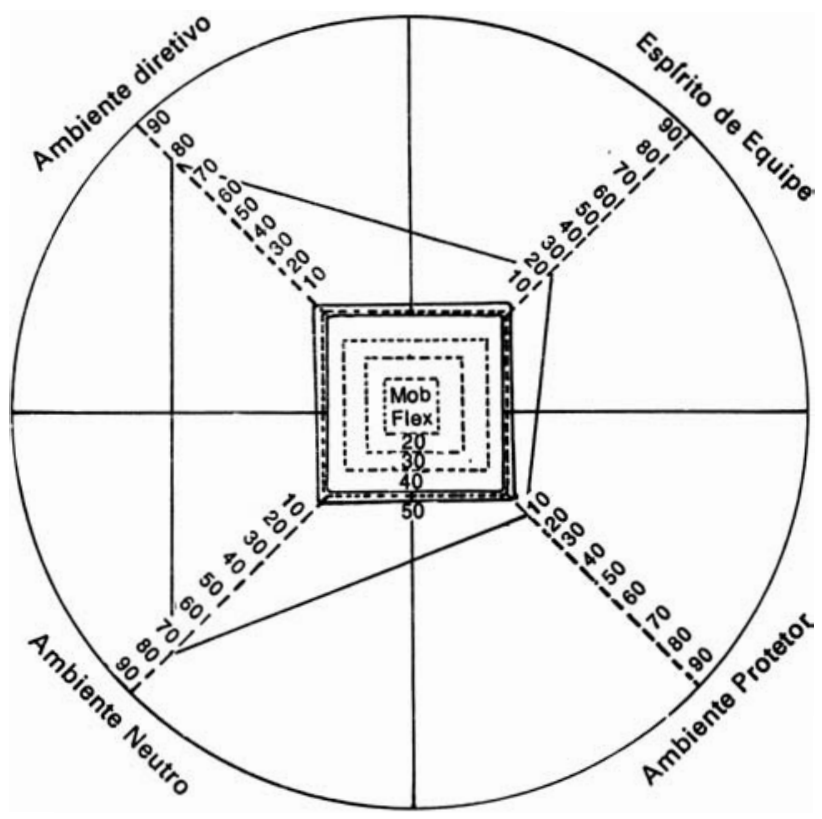

\subsection{Situaçāo Desejável}

Os resultados obtidos através do instrumento, evidenciam que os respondentes desejam com grande intensidade, um ambiente organizacional de espirito de equipe com certa flexibilidade e mobilidade.

O ambiente de espirito de equipe. As decisões, também, são tomadas em nível de cúpula da empresa, no entanto, existe transparência e clareza nos canais de comunicação. Os objetivos da empresa são claramente definidos e conhecidos por todos. Há definição de funções e papéis, assim como as linhas de autoridade e responsabilidade. Os subordinados de menor nivel educacional mostram-se satisfeitos e os de nível educacional mais elevado solicitam maior autonomia em seu trabalho. No processo decisório, a empresa mostra-se receptiva aos anseios e reinvidicações dos subordinados.

A representação GRÁFICA 2 mostra claramente a predominância do ambiente desejado pelos respondentes. 


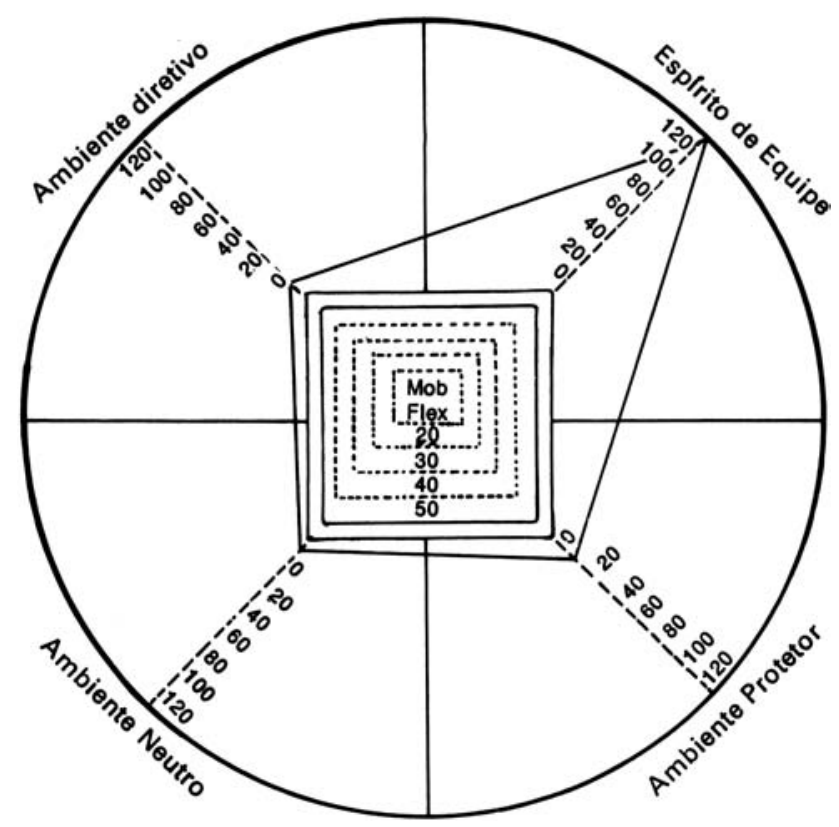

\subsection{Diagnóstico Situacional}

A situação interna da empresa revelada pelos participantes confirma as informaçōes obtidas no exame da cultura e caracteriza-se pelos seguintes aspectos:

A - Plane jamento

Esta fase do processo administrativo praticamente não é desenvolvida pelos enfermeiroschefes em suas unidades de trabalho, porém colaboram com o planejamento geral da Divisão de Enfermagem, fornecendo informaçōes que são solicitadas.

\section{B - Organizaçāo}

Quanto à organização do Serviço de Enfermagem, vários pontos críticos foram levantados, como:

Regimento de Enfermagem desatualizado e inacessivel ao pessoal dos diversos serviços.

Inexistência de Manual de Enfermagem, tanto em nível de direção quanto nos diversos serviços.

Nas diversas unidades, existem normas e rotinas gerais, oriundas de outros serviços, objetivando sistematizar o seu relacionamento e interdependência.

Indefinição de funçōes nos diversos níveis hierárquicos, assim como entre as diversas categorias profissionais.
Falta de coerência entre o nivel de formação das diversas categorias de enfermagem e as atribuições que the são delegadas, no processo de divisão do trabalho. Esta situação, faz com que pessoas com diferentes graus de formação educacional, executem procedimentos da mesma complexidade.

Descontinuidade na direção dos serviços, motivada pela escassez de pessoal qualificado.

C - Liderança e Coordenação

O emprego de mais de uma pessoa para realizar uma atividade, torna necessária a divisão do trabalho, a que deve ser assegurada pela coordenação e liderança. A esse respeito, pontos críticos foram levantados, como:

Centralização do poder e da tomada de decisão, fazendo com que os subordinados se tornem meros executores das ordens emanadas dos escalōes superiores.

As linhas de autoridade e responsabilidade são rigorosamente respeitadas retardando decisōes importantes.

Falta de integração sistêmica entre os diversos serviços, gerando desentendimentos e prejuízos na qualidade.

Distanciamento entre a Direção e a infra-es- 
trutura operacional.

O sistema de acompanhamento das atividades realizadas é feito através de supervisão direta e comunicação verbal e escrita.

A distribuição do trabalho é feita predominantemente de forma verbal, sendo que são raros os serviços que adotam a forma escrita.

Existência de tentativas por parte de pessoas que ocupam cargos de direção em níveis hierárquicos inferiores, de ouvir cs subordinados no processo decisório.

Duplicidade de comando para o pessoal de apoio (serventes, copeiras, secretárias, etc.). A supervisão das atividades executadas é feita pelo enfermeiro, no entanto, hierarquicamente são subordinados a outros serviços.

\section{D - Controle e Avaliaçāo}

CONTROLES ADMINISTRATIVOS:

Nas unidades de intemação são implantados os seguintes controles:

Controle de entorpecentes e psicotrópicos;

Controle da frequência do pessoal; nente;

Controle do material de consumo e perma-

Controle da lotação de pacientes intemados e leitos vagos.

Os três primeiros são executados somente para atender exigências de outros serviços. Inexistem estudos relacionados a custos, consumo, produção, etc., em nível de unidades de assistência.

\section{CONTROLE DE QUALIDADE DOS SERVIÇOS PRESTADOS:}

Apesar de se tratar de um hospital de ensino e um centro de referência do estado, carece de instrumentos que permitam avaliar quantitativa e qualitativamente os serviços prestados.

E - Polftica de Recursos Humanos

- Coexistência de dois vínculos empregatrcios com diferentes níveis salariais e de beneffcios:

- Servidores do quadro permanente possuem plano de cargos e salários, avaliação periódica e outros benefícios assegurados em lei;

- servidores do quadro da fundação não são contemplados por política de recursos humanos;

- Discrepâncias salariais entre os dois quadros para o passoal que desempenha as mesmas funçōes.

- Parcialidade no tratamento do pessoal, gerando insatisfação, conflitos e desmotivação.

- A sistemática de avaliação de desempenho existente, não desempenha de fato o seu papel, uma vez que é realizada:

- considerando-se prioritariamente fatores quantitativos;

- vinculada à progressão funcional (de dois em dois anos);
- sem acompanhamento efetivo e sistemático entre os períodos.

- Por outro lado, o pessoal do quadro da fundação não sofre qualquer tipo de avaliação.

- Existe uma Comissão de Desenvolvimento de Recursos Humanos de Enfermagem, responsável pela programação e desenvolvimento de treinamento e reciclagem do pessoal, e coordenando, também, o Curso de Formação de Auxiliares de Enfermagem.

- Entre os beneff́cios oferecidos pela empresa encontram-se o vale-transporte, vale-refeição (almoço, lanche e ceia notuma), creche para filhos de servidores de 0 a 6 anos de idade, assim como assistência médico-ambulatorial.

\section{Comunicaçāo}

Os instrumentos utilizados na comunicação são: quadro de avisos, livro de ocorrências administrativas, folha de anotaçōes de enfermagem, prontuário do paciente, reuniōes da unidade do serviço e reuniōes gerais com a coordenação e direção de enfermagem.

Além desses instrumentos, são adotadas também comunicações escritas diversas.

\section{GERÊNCIA PARTICIPATIVA: Uma Proposta para Mudança de Ambiente}

Com base no diagnóstico e análise da organização, assim como a identificação de tendência para um estilo gerencial mais democrático, levantou-se uma estratégia, que pode ser implementada em função da situação, e que pode contribuir no processo de renovação do serviço de enfermagem, tendo como pressupostos:

- Integração, como prossuposto filosófico;

- Descentralizaçāo, como diretriz política; rencial.

- Gerência Participativa, como estilo ge-

A integração pressupōe:

- um pensamento diretor definido a partir do consenso do grupo, e em nível das lideranças superiores da empresa;

- um processo que permeia todos os níveis da pirâmide organizacional;

- conhecimento e identificação de todos com a filosofia, políticas, objetivos, metas e linhas de ação da empresa.

A descentralizaçāo pressupōe:

- manutenção da unidade doutrinária em todos os níveis;

- decisão compartilhada como expressão do exercício da democracia no trabalho e de esforços criativos em equipe.

A gerência participativa pressupōe:

- compromisso com a cultura empresarial;

- envolvimento de todos no processo de- 
cisório;

- efetivo desdobramento em todos os niveis da estrutura da organização.

\section{JUSTIFICATIVA}

Os resultados do diagnóstico e da análise da situação estudada, evidenciam que a maioria das dificuldades, decorre basicamente de problemas de administração.

Considerando que o gerente é o agente de mudança por excelência, cujo papel é o de formar equipes, deleger competências, integrar lideranças, conduzir o processo e obter resultados, o grupo optou pela apresentação de uma proposta de desenvolvimento de gerente, em todos os níveis hierárquicos, mediante ação participativa, para renovação da cultura e redimencionamento do modelo organizacional.

\section{PROPÓSITO}

Implementação de uma estratégia renovadora que estimule o reajustamento dos estilos gerenciais, mediante um esforço sistematizado de conscientização dos gerentes que atuam em todos os niveis estruturais da divisão de enfermagem.

\section{AÇĀO METODOLÓGICA}

Para alcançar os propósitos de renovação, a estratégia deve contemplar dupla abordagem:

- Cognitiva-integrativa, visando ampliar o referencial teórico, mediante transferência de conhecimentos de especialistas para o grupo e, deste, para a sua realidade e equipe.

- Psico-motivacional, utilizando técnicas de dinâmica de grupo, para obter participação criativa, envolvendo as seguintes etapas:

1. Processo de conscientizaçāo - posicionar o gerente no contexto cultural e sóciotécnico da empresa,

2. Delineamento de um modelo de estilo gerencial, obtido através de:

2.1 Fundamentação teória (Teorias da administração e sua aplicação na enfermagem);

2.2 Integração psicossocial compatibilizando necessidades individuais e organizacionais (aspectos motivacionais).

2.3 Cultura empresarial (filosofia, politicas, objetivos, linhas de ação e realidade situacional).

2.4 Estrutura técnica e organizacional - instrumentos necessários às intervenções renovadoras.

3. Diagnósticos setoriais e intervençōes renovadoras, mediante:

3.1 Descrição e análise minuciosa dos setores de atuação dos participantes e definição de linhas estratégicas de ação.

3.2 Aplicações no campo de atuação, sob orientação e autorização.

3.3 Avaliação e revisão das estratégias implementadas, através de análise crítica e dis- cussão em grupo, com vistas a correçoes, ajustes e enriquecimento.

\subsection{Detalhamento de programaçāo}

a) Exploraçāo do potencial da equipe

Entrevistas individuais, com levantamento do curriculum vitae, das condiçōes motivacionais e do potencial de crescimento dos participantes.

Dinâmica de grupo, com ênfase em desenvolvimento gerencial e organizacional, e conceituações básicas, objetivando criar uma linguagem comum.

\section{b) Fundamentação teórica}

Para aprofundamento conceitual e tentativa de conclusões acerca da realidade da empresa.

\section{c) Seminários}

Para revisão, reforço da conceituação básica e análise crítica dos resultados.

d) Construção do modelo gerencial

Baseado no referencial teórico, reflexão sobre a realidade e consenso do grupo.

e) Aplicaçāo experimental do modelo

Us participantes implementarão o modelo, no seu campo de atuação (sob orientação). cesso

f) Seminário de revisão geral do pro-

4.2 Suporte teórico durante o processo

No periodo experimental, sugere-se para embasamento teórico do grupo, temas relacionados às necessidades previamente detectadas, bem com assuntos voltados para:

a) Cultura organizacional;

b) Teorias da administração e sua aplicação no serviço de enfermagem.

c) Filosofia gerencial e do serviço de enfermagem;

d) Estilos gerenciais com ênfase na gerência participativa.

e) Instrumentos gerenciais:

- delegação de autoridade,

- supervisão em diferentes niveis

- sistema de reuniōes programadas (dirigir e participar)

- avaliação de desempenho

- avaliação da qualidade assitencial

f) Gerência de grupos de trabalho, com enfoque metodológico.

g) Administração de conflitos:

- Resistência, integração, negociação e relações de trabalho.

h) Inovação e criatividade.

Os temas serão desenvolvidos seguindo os seguintes passos:

19) Exposiçāo

29) Debate com o expositor

39) Grupos de discus. (adequar os conceitos à realidade da situaçăo de trabalho)

49) Apresentaçäo das conclusíes em plenário, pelos relatores. 
5\%) Reuniāo dos relatores para consenso redação final.

69) Aprovação pelo plenário da viabilidade de aplicação.

\section{CONCLUSĀO DO ESTUDO}

A análise dos resultados permitiu levantar aspectos relevantes no que diz respeito à cultura organizacional de um hospital de ensino, do ponto de vista de enfermeiros-chefes de unidades de assistência.

Considerando as maiores freqüências nas respostas, a situação real caracteriza-se por um ambiente diretivo e neutro. Enquanto que a si- tuação desejável, projeta-se prioritariamente para um ambiente de esplrito de equipe com certa mobilidade e flexibilidade.

Considerando a mudança como uma referência constante e desafiadora, torna-se imprescindível que a organização se arme de condições efetivas para interpretá-la e processá-la adequadamente.

Com base nos resultados obtidos, assim como na identificação de tendência para um estilo gerencial mais democrático, elaborou-se uma proposta de desenvolvimento de gerentes, que implementada, poderá contribuir no processo de renovação da cultura e redimensionamento do modelo organizacional.

\section{REFERÊNCIAS BIBLIOGRÁFICAS}

1 AQUINO, Cleber Pinheiro de. Adrninistração de recursos hwmanos. São Paulo: Atlas, 1980.

2 FISCHER, Fleury. Cultura e poder nas organizaçōes. São Paulo: Atlas, 1990.

$3 \mathrm{KRON}$, Thora. Administração dos cuidados ao paciente. Rio de Janeiro: Inter Livros, s/d.

4 MATA, Fernando. Teorias das organizaçōes. São Paulo: Atlas, s/d.

5 MATOS, Francisco Gomes. Gerência participativa. Rio de Janeiro: Livros Técnicos e Cientfficos, 1979.
6 MATOS, Francisco Gomes. Reciclagem situacional. 2. Ed. Rio de Janeiro: Livros Técnicos e Científicos, 1981.

7 МО ГA, Fernando. Teoria geral da adıninistração. São Paulo: Pioneira, s/d.

8 PERROW, Charles B. Análise organizacional: um enfoque sociológico. São Paulo: Atlas, 1976.

9 KOOГZ, Harold. Avaliação de executivos. Coleção Administração e gerência. v. 13. 


\section{ANEXO ${ }^{\circ}$ \\ INSTRUMENTAÇĀO DE COLETA DE DADOS \\ CULTURA DA ORGANIZAÇĀO}

Neste instrumento você encontrará 10 conjuntos de afirmações, cada um versando sobre um aspecto importante da cultura de uma organização. Cada conjunto se compöe de 5 afirmações: $A, B, C, D$, e $E$.

Nos traços colocados à esquerda das afirnnações, marque com um " $R$ ", aquela que melhor representa o clima da empresa, de acordo com a maneira como vock vê a sua empresa (não pense em como sua empresa deveria funcionar, mas sim em como ela realmente funcio na).

Marque com um " $D$ " o clima que você acha certo ou desejável, aquele que reflete o seu pensamento sobre como sua empresa deveria funcionar. Eventualmente, o real e o desejável poderão ser o mesmo, neste caso marque "RD".

Agora, começe a responder. Não há tempo determinado para concluir, mas procure ser sincero e rápido.

\section{1) OBTENÇĀO DE RESULTADOS PELA EMPRESA}

A - Enfocam-se os problemas da empresa, levando-se em conta seus efeitos econômicos, com o mínimo de interesse pelo seu impacto sobre o pessoal da empresa.

B — As açōes empreendidas na solução dos principais problemas são tomadas visando principalmente o cumprimento dos objetivos da empresa.

C — Os problemas somente se resolvem quando já é impossível continuar a adiá-los e quando já se perdeu a esperança de que o passar do tempo venha a solucioná-los naturalmente.

D — As reações aos problemas surgidos são dirigidas para se conseguir um bom relacionamento humano, procurando-se com isso incrementar a eficácia e a produtividade no trabalho.

E - Ao se tratarem os principais problemas surgidos, verificam-se as implicações do mesmo nos objetivos da empresa sem deixar de observar os efeitos e as consequências que terão sobre os recursos humanos; as soluções são dadas de forma a harmonizar os objetivos da empresacom os dos seus recursos humanos.

\section{2) LUCROS E DESPESAS DA ORGANIZAÇĀO}

A — O pessoal é constantemente pressionado para que, no seu trabalho, dê absoluta prioridade aos lucros e às despesas da organização.

B — Há pouco conhecimento objetivo, por parte do pessoal envolvido, sobre problemas relativos a lucros e despesas da empresa; pessoas envolvidas diretamente com isso não recebem informações sobre tais aspectos.

$\mathrm{C}$ - As preocupações com um bom relacionamento humano prevalecem sobre as considerações de lucros e despesas da organização.

D — O pessoal da empresa está consciente de que sua atuação afeta os lucros e as despesas da empresa e, através desse conhecimento, é motivado para a redução dos custos e a elevação dos lucros.

E - Mantém-se um bom equilßorio entre a importância que se dá às necessidades do pessoal e àquela que se concede aos lucros e despesas da organização. 


\section{3) PRODUTIVIDADE DO PESSOAL}

A Geralmente se permite que o pessoal determine por si mesmo o que se considera padrões satisfatórios de produtividade e trabalhe segundo tais padróes.

B - Considera-se que o pessoal da empresa tem o direito de sentir-se seguro e satisfeito no trabalho. Conserva-se na empresa, mesmo aquele empregado que se revelou ineficiente e improdutivo, na tentativa de elevar seu moral e melhorar sua produtividade.

C — Procura-se obter um máximo de eficácia e produtividade no trabalho. O pessoal que se revela incompetente e não consegue atingir os padrōes de desempenho estabelecidos geralmente não permanece na empresa.

D - As decisões sobre os recursos humanos da empresa são tomadas pensando-se exclusivamente no presente, sem muita consideração com o potencial humano para o futuro. Leva-se em conta quase sempre apenas as necessidades de produção imediata. $O$ pessoal existente parece ser suficiente para se obter essa produção, mas geralmente é preciso exercer certa pressão sobre o pessoal para conseguí-la.

E - Existem recursos humanos suficientes para realizar o trabalho dentro dos padrōes aceitáveis, sem a necessidade de exercer nenhuma pressão.

\section{4) PLANEJAMENTO}

A — Os planos são feitos principalmente a curto prazo e se baseiam quase sempre no desempenho passado. Prognósticos futuros quase não são levados em consideração no planejamento; há muita ênfase na produtividade.

B — Os planos são aprovados na cúpula da empresa, não se levando em conta as opiniōes e sugestões eventualmente feitas pelas pessoas "debaixo", diretamente afetadas por tais planos.

$\mathrm{C}-\mathrm{O}$ planejamento é feito procurando-se fazer com que eventuais divergências entre os invíduos envolvidos, sejam contornadas e não venham a ocasionar conflitos. Delegam-se responsabilidades de tal forma que o pessoal não se sinta pressionado a cumprir o plane jado.

D — Não existe um efetivo planejamento do trabalho; as ações empreendidas se baseiam mais na necessidade urgente de resolver determinados problemas, conforme estes se apresentam.

E - O planejamento se faz com base na análise racional dos problemas e das situações existentes previstas no futuro. Os objetivos e metas e os programas de trabalho são suficientemente flexíveis para permitir a incorporação de sugestões das pessoas afetadas. Dá-se importância às contribuições individuais no planejamento.

\section{5) CONTROLE}

A — O controle é exercido através de compreensão e comum acordo entre chefes e subordinados. Faz-se uma análise cuidadosa de por que, como e para que se executa cada trabalho. O pessoal está permanentemente inteirado de qual é a sua situação específica e desempenho na empresa.

B — Existe um rígido e contínuo sistema de relatórios escritos e verbais, através do qual os chefes se mantêm informados. O pessoal recebe instruções sobre o que tem a fazer, mas necessariamente sobre por que tem que fazê-lo. 
C _ As pessoas trabalham por si so; o controle é exercido apenas excepcionalmente, aprecendo sobretudo nas ocasiões em que problemas se manifestam.

D — Quase sempre se tenta conseguir que o pessoal execute seu trabalho através do fornecimento de elogios. As criticas ou opiniōes em relação ao trabalho executado são raras ou inexistentes.

E - Os pontos fracos e fortes do pessoal são analisados por seus supervisores, sobretudo para prevenir que se afastemdas normas de trabalho vigentes e dos resultados previstos.

\section{6) COORDENAÇĀO}

A Os diferentes departamentos agem como entidades independentes entre si. A troca de informaçōes entre o pessoal e a empresa se realiza predominantemente através dos canais formais de comunicação.

B — Quase não existe coordenação entre os diversos departamentos da empresa, cada qual funcionando de maneira isolada, como bem entende, e sem levar em conta as necessidades dos demais.

C — Nas relações entre o pessoal e entre departamentos, dá-se uma grande importância ao entendimento mútuo em tomo dos objetivos e metas principais da organização.

D _ Para se solucionarem problemas de trabalho, levam-se em conta principalmente os antecedentes, a personalidade dos indivíduos envolvidos e os objetivos e metas; fomenta-se a integração de departamentos diferentes e a elaboração de planos conjuntos.

E — É fácil perceber que existe, na empresa, um esforço constante e comum para abafar e reduzir ao mínimo os conflitos entre o pessoal e para se conseguir a máxima harmonia possível entre todos.

\section{7) AVALIAÇÃO}

A — Fazem-se análises e relatórios visando avaliar a qualidade do trabalho, às vezes através da comunicação informal (extra-oficial). Há uma autêntica troca de idéias entre chefes e subordinados, visando dar conhecimento, quando necessário, para melhorar o desempenho.

B - Quando se conclui um trabalho ou uma fase importante de um trabalho, procura-se avaliá-lo através de um exame do que foi feito, a fim de observar se houve falhas. Procura-se geralmente, localizar quem errou e em que fase do trabalho, punindo-se os culpados.

C — Estimula-se e elogia-se com freqüência o pessoal pelo bom trabalho realizado. Procura-se avaliar o trabalho àmedida que se desenvolve, a fim de detectar situações em que esses estímulos possam ser proporcionados. Raramente são feitas críticas.

D — Raramente se fazem apreciações sobre o trabalho executado, ou críticas ou elogios de qualquer espécie.

E - Fazem-se criticas sinceras sobre o trabalho, assinalando os erros e tratando de reduzi-los. Quando um trabalho é conclurdo, fazem-se análises, visando encontrar melhores soluções e lograr melhores resultados. 


\section{8) COMUNICAÇĀO}

A — O pessoal está sempre bem informado dos planos e decisões da empresa e é convidado a participar deles, podendo expressar livremente seus pontos de vista. As informações fluem rapidamente e sem distorções entre os gerentes, entre estes e seus subordinados e de subordinados e superiores. As diferenças de opiniōes são resolvidas de comum acordo.

B — A comunicação existente é somente a de rotina e a mínima necessária. Assim a comunicação não é profunda e nem ampla. Os indivíduos podem expressar suas opiniōes, porém, estas frequentemente não são ouvidas ou não são levadas em conta. Os subordinados não se mostram inclinados a convencer seus superiores de seus pontos de vista ou opiniōes.

C — A comunicação informal (boatos, rumores) é um importante veŕculo de comunicação na empresa. Fazem-se freqüentes reuniōes informais. Freqüentemente misturam-se outros assuntos com os assuntos de trabalho nas entrevistas e reuniōes.

D — O pessoal E informado apenas do indispensável para executar seu trabalho. São raras as ocasiōes em que se comentam assuntos não relacionados com trabalho. Os subordinados devem manter seus superiores informados.

E — A comunicação existente é basicamente necessária para que o pessoal faça seu trabalho. Algumas informações são formecidas pelos subordinados aos seus superiores. Ocasionalmente há reuniões para discussão de problemas de trabalho.

\section{9) TRATAMENTO E SOLUÇĀO DE CONFLITOS}

A — Quase não existem desacordos entre as pessoas, porque estas evitam entrar em polêmicas ou tratar de assuntos que poderiam gerar controvérsias e dificuldades pessoais.

B - As pessoas tomam cuidado em não deixar aflorar seus conflitos e irritações pessoais, procurando sempre conservar a amizade e a harmonia, mesmo que isso exija ignorar seus pontos de vista.

C - Discutem-se os problemas de tal forma que a maior parte das pessoas acabe aceitando as soluçōes, da maneira como foram apresentadas. Quando as pessoas envolvidas se mantêm firmes em seus pontos de vista, o tratamento do problema sofre um esfriamento, adiando-se sua solução para voltar mais tarde ao problema.

D — Os conflitos são enfrentados aberta e sinceramente, examinando-se suas causas e tratando-se de solucioná-los razoavelmente, de maneira que não voltem a aparecer e que ninguém fique magoado.

E Usam-se freqüentemente a autoridade e a hierarquia como meio de solucionar conflitos entre pessoas ou departamentos. Geralmente os desacordos são resolvidos por arbitração superior ou pela adoção das idéias do superior.

\section{0) CRIATIVIDADE}

A - Qualquer idéia sugerida é ouvida e acatada. Percebe-se na empresa uma atitude de grande receptividade a praticamente tudo o que é sugerido ou proposto.

B — Idéias e sugestões feitas pelo pessoal são aceitas apenas quando estão de acordo com os objetivos e metas da empresa. 
C —_ As boas contribuições feitas pelo pessoal são recompensadas e postas em prática. As contribuiçōes sem aplicação prática são rejeitadas e seus autores informados de por que o foram e motivados a apresentar outras.

D — As pessoas procuram não apresentar novas idéias, opiniōes ou sugestōes.

$\mathrm{E}$ - Recusam-se sistematicamente quase sempre as novas idéias, opiniōes e sugestōes do pessoal.

\section{ANEXO II}

\section{ROTEIRO DA ENTREVISTA}

1) Qual é a sua função na Divisão de Enfermagem?

2) Há quanto tempo você trabalha neste hospital?

3) Quem é o seu chefe imediato?

4) Quem mais lhe dá instruções?

5) Quem são seus subordinados diretos?

6) Quem mais dá instruções aos seus subordinados?

7) Costuma ter oportunidade de discutir suas idéias com a direção?

8) Descreva o seu trabalho.

9) Existe plane jamento a médio e a longo prazo em seu trabalho?

10) Como, habitualmente, você toma decisões e, de que modo, são comunicadas aos seus subordinados?

11) Quanto à organização do serviço, existem normas e rotinas escritas, manual de enfermagem, regimento intemo e outros? Como é feita a distribuição de atividades aos funcionários?

12) Como você caracteriza o seu relacionamento com os seus subordinados?

13) Como é feito o acompanhamento das atividades executadas em sua Unidade de trabalho?

14) Quais são os controles que você executa em sua Unidade de trabalho?

15) Como é feita a avaliação de desempenho dos funcionários do hospital?

16) Como são desenvolvidas as atividades de educação continuada dos funcionários?

17) Como é feita a distribuição de tarefas aos subordinados?

18) Quais as dificuldades encontradas em seu trabalho?

\section{ANEXO III}

\section{TABULAÇĀO DOS RESULTADOS}

Nas tabelas 1 e 2 estão resumidos os valores que foram atriburdos aos respondentes às afirmações dos 10 conjuntos, sobre a Cultura Organizacional, considerando as situações real e dese jável da empresa.

Tabela 1 - Situação Real da Empresa Hospital de Ensino X Curitiba, 1988

\begin{tabular}{|c|c|c|c|c|c|}
\hline $\begin{array}{c}\text { Aspectos } \\
\text { da } \\
\text { Cultura }\end{array}$ & 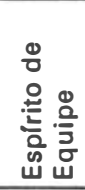 & 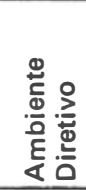 & 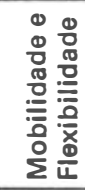 & 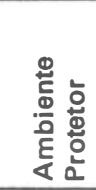 & 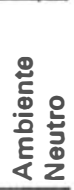 \\
\hline 1 & B 06 & $A 03$ & $\mathrm{E} 02$ & D $\underline{03}$ & $\mathrm{C}_{0.07}$ \\
\hline 2 & $D \underline{01}$ & $\mathrm{~A} \underline{03}$ & $E \underline{03}$ & C $\underline{00}$ & B 14 \\
\hline 3 & $c \underline{\overline{03}}$ & $D \underline{09}$ & $E \underline{01}$ & B $\overline{05}$ & $A 03$ \\
\hline 4 & E 03 & B $\overline{07}$ & $A \underline{02}$ & C 01 & $D, 08$ \\
\hline 5 & A 01 & B 09 & E $\overline{04}$ & $D \underline{04}$ & C.03 \\
\hline 6 & c 02 & A 10 & $D 00$ & E 02 & B 07 \\
\hline 7 & E. 05 & B 02 & A 04 & C 00 & D. 10 \\
\hline 8 & A 04 & B 06 & E 07 & C. 04 & D 00 \\
\hline 9 & D 02 & E 10 & C 07 & $\mathrm{~B} 00$ & A 02 \\
\hline 10 & C 03 & $E \underline{03}$ & В $\underline{09}$ & A 00 & D 06 \\
\hline TOTAL & 30 & 62 & 39 & 12 & 60 \\
\hline
\end{tabular}


Tabela 2 - Situação Desejável da Empresa Segundo os Investigados.

\begin{tabular}{|c|c|c|c|c|c|}
\hline Conjuntos & 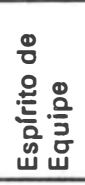 & 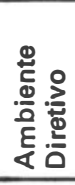 & 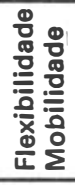 & 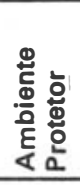 & 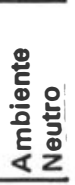 \\
\hline $\begin{array}{r}1 \\
2 \\
3 \\
4 \\
5 \\
6 \\
7 \\
8 \\
9 \\
10\end{array}$ & $\begin{array}{ll}\text { B } & 00 \\
\text { D } & 11 \\
\text { C } & 05 \\
\text { E } & 20 \\
\text { A } & 16 \\
\text { C } & 09 \\
\text { E } & 10 \\
\text { A } & 18 \\
\text { D } & 18 \\
\text { C } & 15\end{array}$ & $\begin{array}{ll}A & 01 \\
\text { A } & 00 \\
\text { D } & 04 \\
\text { B } & 00 \\
\text { B } & 00 \\
\text { A } & 00 \\
\text { B } & 00 \\
\text { B } & 00 \\
\text { E } & 01 \\
\text { E } & 00\end{array}$ & $\begin{array}{ll}\text { E } & 16 \\
\text { E } & 07 \\
\text { E } & 10 \\
\text { A } & 00 \\
\text { E } & 05 \\
\text { D } & 08 \\
\text { A } & 08 \\
\text { E } & 02 \\
\text { C } & 02 \\
\text { B } & 03\end{array}$ & $\begin{array}{ll}\text { D } & 04 \\
\text { C } & 03 \\
\text { B } & 02 \\
\text { C } & 01 \\
\text { D } & 00 \\
\text { E } & 04 \\
\text { C } & 01 \\
\text { C } & 00 \\
\text { B } & 00 \\
\text { A } & 03\end{array}$ & $\begin{array}{ll}C & 00 \\
B & 00 \\
A & 00 \\
D & 00 \\
C & 00 \\
\text { B } & 00 \\
\text { D } & 02 \\
\text { D } & 01 \\
\text { A } & 00 \\
\text { D } & 00\end{array}$ \\
\hline TOTAL & 122 & 06 & 61 & 18 & 03 \\
\hline
\end{tabular}

